\title{
Adaptive Pitch Control of Wind Turbine for Load Mitigation under Structural Uncertainties
}

\author{
Yuan Yuan \\ Graduate Research Assistant and Ph.D. Candidate \\ Department of Mechanical Engineering \\ University of Connecticut \\ 191 Auditorium Road, Unit 3139 \\ Storrs, CT 06269 \\ USA \\ J. Tang $^{\dagger}$ \\ Professor \\ Department of Mechanical Engineering \\ University of Connecticut \\ 191 Auditorium Road, Unit 3139 \\ Storrs, CT 06269 \\ USA \\ Phone: (860) 486-5911, Email: jtang@engr.uconn.edu
}

\section{Submitted to Renewable Energy \\ (Revised)}

${ }^{\dagger}$ Corresponding author

(C) 2016. This manuscript version is made available under the Elsevier user license http://www.elsevier.com/open-access/userlicense/1.0/ 


\title{
Adaptive Pitch Control of Wind Turbine for Load Mitigation under Structural Uncertainties
}

\author{
Yuan Yuan and J. Tang ${ }^{\dagger}$ \\ Department of Mechanical Engineering \\ University of Connecticut \\ Storrs, CT 06269, USA \\ Phone: +1 (860) 486-5911, Email: jtang@engr.uconn.edu
}

\begin{abstract}
In this research, a new adaptive control strategy is formulated for the pitch control of wind turbine that may suffer from reduced life owing to extreme loads and fatigue when operated under high wind speed and internal structural uncertainties. Specifically, we aim at making a trade-off between the maximum energy captured and the load induced. The adaptive controller is designed to both regulate generator speed and mitigate component loads under turbulent wind field when blade stiffness uncertainties exist. The proposed algorithm is tested on the NREL offshore 5-MW benchmark wind turbine. The control performance is compared with those of the gain scheduled proportional integral (GSPI) control and the disturbance accommodating control (DAC) that are used as baselines. The results show that with the proposed adaptive control the blade root flapwise load can be reduced at a slight expense of optimal power output. Moreover, the blade load mitigation performance under uncertain blade stiffness reduction is improved over the baseline controllers. The control approach developed in this research is general, and can be extended to mitigating loads on other components.
\end{abstract}

Keywords: wind turbine, pitch control, load mitigation, adaptive control, turbulent wind field, uncertainties.

\section{Introduction}

Wind energy is commonly recognized as a major environmentally friendly energy source that is renewable. Modern wind turbines are large, flexible structures operating in highly turbulent and sometimes unpredictable wind field [1]. There are three regions in wind turbine operation (Figure 1). In Region 1 where wind speed is very low, the brake is equipped to stop the wind turbine operation, yielding no power generation. In Region 2, from the cut-in wind speed to the cut-out speed, the objective is to achieve the maximum power output, i.e., to maximize the aerodynamic power coefficient $C_{p}$. The

\footnotetext{
${ }^{\dagger}$ Corresponding author
} 
generator torque control is utilized to track the optimal tip speed ratio in specific $C_{p}$ curve which is

34 usually obtained from benchmark test data. In Region 3 where wind speed is high, the objective is to track the rated generator speed. There generally exists a trade-off between tracking the generator speed (i.e., power output) and maintaining the mechanical loads to turbine components (e.g., blades), due to the significant uncertainties in operating conditions and system properties. Such external and internal uncertainties include varying wind speeds, weather changes, icing, assemblage error of the turbine, and rotor asymmetries caused by damaged in blades, etc. Intuitively, the long-term productivity of a wind turbine may be higher if it is operated somewhat conservatively at the presence of these uncertainties.

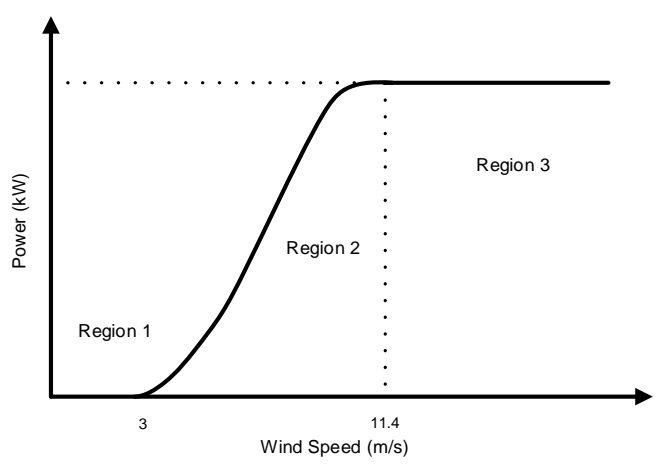

Figure 1. Three regions of a typical wind turbine. approach to regulate the generator speed, and a gain scheduling part was added to deal with the integral (GSPI) control [2]. Wright investigated the state-space feedback control after linearizing the nonlinear model under selected operating points. As the model depends on the operating point selection and wind disturbance may not be directly measured, a Disturbance Accommodating Control (DAC) was developed to achieve disturbance rejection and to attenuate loads by accounting for wind disturbances with additional state estimators [3]. Nevertheless, the actual performance may still be affected by the wind estimator accuracy, and the wind speed disturbances cannot be precisely cancelled out in high-order controllers [4]. Also the wind disturbance gain should be redefined to track the set-point. Frost et al employed an adaptive control for speed regulation, which does not require knowing precisely the wind turbine model parameters [5]. Connor et al formulated an $H_{\infty}$ controller to mitigate fatigue damage of wind turbine with known linear model [6]. As the wind speed varies, the linear model is no longer time- 
invariant. Stol and Balas thus extended the periodic DAC based on time-varying turbine model, aiming at improving blade load attenuation level [7]. To better reject wind disturbance, Hand and Balas further incorporated properties of coherent turbulent inflow structures to DAC to mitigate the transient blade load response caused by the Rankine vortex in the flow [8]. Since it is difficult to optimize all performance metrics simultaneously, Model Predictive Control (MPC) was proposed to realize trade-off between multiple objectives [9-11]. In order to realize better balance of the conflicting objectives such as power capture and tower fore-aft fatigue load in the entire operating region, multi-objective MPC tuned by Pareto curves was formulated [12-13]. In addition, the dynamic inflow can be included in the prediction model of MPC design to facilitate the robustness of the controller [14].

Along with the hardware advancement in newer wind turbines, there have also been recent studies focusing on individual blade pitch control to attenuate blade root loads to counteract wind shear and asymmetric disturbance across the rotor disc [15-17]. Hassan investigated a mixed $H_{2} / H_{\infty}$ with pole placement to regulate generator speed and reduce once-per-revolution (1P) load [18]. More recently, light detection and ranging (LIDAR) system has been developed to remotely measure the incoming wind speed [19]. Using LIDAR measurement, Dunne and Pao [20] designed a combined feedback/feedforward blade pitch controller to reduce the structural loads in blade root, tower base and top. In another study, FXRLS-based feedforward control was suggested to mitigate both blade bending and tower moment while regulating the rotor speed with slightly sacrificed energy, which takes the advantage of the robustness characteristics and good disturbance rejection of the adaptive control [21].

In wind turbine blade pitch control, the fundamental challenge stems from the nonlinearity of the model, unmodeled dynamics, as well as the internal and external uncertainties [22-23]. Conceptually, the strategy of adaptive control is appealing in tackling such challenge, as it has the potential of dealing with highly nonlinear model with unknown parameters and complicated operating conditions. Indeed, this strategy has been explored on wind turbines to achieve different goals. In order to realize the maximum power at below-rated wind speeds (Region 2), Johnson et al presented an adaptive pitch controller to obtain high aerodynamic efficiency by using a discrete hill-climbing method [24]. Balas et al developed an adaptive Disturbance Tracking Control (DTC) technique to track the optimal tip speed ratio based on a wind speed estimator with the linearized CART model [25]. Magar and Balas employed a simplified model in adaptive control design, and demonstrated performance robustness in tracking optimal tip speed ratio under various operating conditions [26].

In this research, we take into consideration the varying wind speeds and model uncertainties, and aim at striking a balance between tracking the generator speed (i.e., near-term performance) and mitigating mechanical loads (i.e., long-term reliability). We investigate the collective pitch control that can be applied to many existing wind turbines. We specifically focus on above-rated wind speeds, and assume 
the turbine is subjected to blade stiffness reductions (possibly caused by minor damage). Specifically, a model reference adaptive controller is formulated towards this goal. Mathematically, our control objective is to balance the generator speed-tracking and the structural loads under blade stiffness uncertainties. A closed-loop system based on the DAC strategy that is originally suggested by Lee and Balas [34] is selected as the reference model in the adaptive control. The reference signal is essentially the outcome of a trade-off between the generator speed and structural loads, acquired based on an optimal control of flapwise deflection modes and generator speed modes through selecting proper weighting matrices. The reduction in flapwise moment at the slight expense of fluctuation of power and generator speed can lead to the aforementioned trade-off. Meanwhile, adaptive control strategy has the capability of dealing with various uncertainties by online updating the parameters at every sampling step according to the difference of the nominal output and reference output while maintaining the stability robustness. While our formulation is mainly based on blade load consideration, the approach can be extended to loads on other components.

The rest of the paper is organized as follows. In Section 2 we briefly introduce the 5-MW benchmark wind turbine model employed. The two existing controllers, i.e., the GSPI control and the DAC approach, are outlined in Section 3, followed by the new adaptive control proposed. Case studies are presented in Section 4. In this research both the model development and the case simulations are conducted by using 111 the Fatigue, Aerodynamics, Structures, and Turbulence (FAST) code [29]. The performance resulted

112 from the new adaptive control are compared with those from the baseline GSPI controller and DAC 113 controller. Section 5 summarizes the concluding remarks.

\section{Model Development}

116 We employ the NREL offshore 5-MW benchmark wind turbine in this research, which is a popular 117 choice in related studies $[2,18,20,26]$. This is a three-bladed, upwind, variable-speed variable blade118 pitch-to-feather-controlled horizontal axis turbine [2]. The rotor diameter is $126 \mathrm{~m}$, and the hub height is $11990 \mathrm{~m}$. The cut-in wind speed is $3 \mathrm{~m} / \mathrm{s}$, the rated wind speed is $11.4 \mathrm{~m} / \mathrm{s}$, and the cut-out wind speed is 25 $120 \mathrm{~m} / \mathrm{s}$. The rated generator speed is $1173.7 \mathrm{rpm}$. We additionally assume a rigid tower, a rigid hub and 121 locked yaw position.

122 A variable-speed wind turbine generally consists of blades, a low speed shaft, a gearbox, a high speed 123 shaft, and a generator. The aerodynamic power captures by the rotor is given as [1]

$$
P_{\text {wind }}=\frac{1}{2} \rho \pi R^{2} C_{p}(\lambda, \beta) v^{3}
$$


where $R$ is the rotor radius and $\rho$ is the air density. The power coefficient $C_{p}$ is a nonlinear function of

126 the tip speed ratio $\lambda$ and the pitch angle $\beta$, and can be obtained from look-up table generated by filed 127 test data. Here

$$
\lambda=\frac{\omega_{r} R}{v}
$$

144 where

where $v$ is the wind speed and $\omega_{r}$ is the rotor speed. From Equations (1) and (2) we can see that the aerodynamic coefficient depends on wind speed, rotor speed and blade pitch angle. Pitch angle control can be used to limit the aerodynamic power captured by the rotor to realize load mitigation. The aerodynamic torque applied to the rotor can be expressed as

$$
T_{a}=\frac{1}{2} \frac{\pi C_{p}(\lambda, \beta) \rho R^{2} v^{3}}{\omega_{r}}
$$

When we assume that the low speed shaft is rigid, we have the equations of motion for the rotor and the generator as, respectively,

$$
J_{r} \dot{\omega}_{r}=T_{a}-C_{r} \omega_{r}-T_{l s}, \quad J_{g} \dot{\omega}_{g}=T_{h s}-C_{g} \omega_{g}-T_{e m}
$$

where $J_{r}$ and $J_{g}$ are the moment of inertia of the rotor and that of the generator, $\omega_{g}$ is the generator speed, $T_{l s}$ and $T_{h s}$ are the low speed shaft torque and high speed shaft torque, $C_{r}$ and $C_{g}$ are the external damping coefficient of the rotor and that of the generator, and $T_{e m}$ is the generator electromagnetic torque. We assume an ideal gearbox (i.e., 100\% efficiency) with the transmission ratio $n_{g}$ given as

$$
n_{g}=\frac{T_{l s}}{T_{h s}}=\frac{\omega_{g}}{\omega_{r}}
$$

Substituting Equation (5) into Equation (4) yields a simplified relation

$$
J_{t} \dot{\omega}_{r}=T_{a}-K_{t} \omega_{r}-T_{g}
$$

$$
J_{t}=J_{r}+n_{g}^{2} J_{g}, \quad K_{t}=K_{r}+n_{g}^{2} K_{g}, \quad T_{g}=n_{g} T_{e m}
$$

The governing equation (i.e., Equation (6)) can represent dynamics in all operating regions. It indicates that the generator speed can be regulated by the aerodynamic torque $T_{a}$ and the electromagnetic torque $T_{e m}$. Hence, two separate SISO control loops, i.e., torque controller and blade pitch controller, can be used. Usually in Region 2, torque controller is utilized to regulate the generator speed while the blade pitch angle is held constant to maintain the maximum aerodynamic coefficient. In above-rated region (i.e., Region 3), however, pitch controller is often implemented to limit the aerodynamic torque $T_{a}$ to avoid 
extreme loads. Here we adopt the torque controller suggested by Jonkman et al [2] that was designed for the same NREL 5-MW benchmark wind turbine, and focus on the blade pitch control.

Observing Equation (3), one can see that there exists complex nonlinear relation between the pitch angle $\beta$ and the aerodynamic torque $T_{a}$. In addition, the flapwise vibration of a blade caused by aerodynamic load needs to be suppressed to avoid damage. Therefore a more accurate dynamic model including the flap mode is needed. In this research we employ the FAST code developed by National Renewable Energy Laboratory (NREL) [29] to establish the mathematical model of the wind turbine. The nonlinear aero-elastic equation of motion can be expressed as [29],

$$
\mathbf{M}(\mathbf{q}, \mathbf{u}, t) \ddot{\mathbf{q}}+\mathbf{f}\left(\mathbf{q}, \dot{\mathbf{q}}, \mathbf{u}, \mathbf{u}_{d}, t\right)=0
$$

where $\mathbf{M}$ is the mass matrix, $\mathbf{f}$ is the nonlinear forcing function vector that includes the stiffness and damping effects, $\mathbf{q}$ is the response vector, $\mathbf{u}$ is the vector of control inputs, $\mathbf{u}_{d}$ is the vector of wind disturbance, and $t$ is time. In our analysis, $\mathbf{f}$ is calculated by using AeroDyn through the Blade Element Momentum (BEM) Theory [28]. In this approach, aerodynamic forces and moments are calculated in each segment of the blade, and the distributed forces are obtained by integration from blade root to tip. FAST then numerically linearizes Equation (8) by perturbing each variable about their respective operating points. After the Taylor series expansion, we obtain

$$
\mathbf{M} \ddot{\mathbf{q}}+\mathbf{C} \dot{\mathbf{q}}+\mathbf{K q}=\mathbf{F u}+\mathbf{F}_{d} \mathbf{u}_{d}
$$

where $\mathbf{M}, \mathbf{C}$, and $\mathbf{K}$ are, respectively, the linearized mass, damping, and stiffness matrices, $\mathbf{F}$ is the control input vector and $\mathbf{F}_{d}$ is the wind disturbance vector.

Here we employ the linearized model that is simplified from the nonlinear model of the actual wind turbine, which is obtained when the first flapwise blade mode DOF (degree-of-freedom), the generator DOF, and the drivetrain torsional flexibility DOF are switched on. One can cast the linearized equation into the state-space representation,

$$
\begin{aligned}
& \dot{\mathbf{x}}=\mathbf{A x}+\mathbf{B u}+\mathbf{B}_{d} \mathbf{u}_{d} \\
& \mathbf{y}=\mathbf{C x}+\mathbf{D u}+\mathbf{D}_{d} \mathbf{u}_{d}
\end{aligned}
$$

where $\mathbf{x}=\left[\mathbf{q}^{T}, \dot{\mathbf{q}}^{T}\right]^{T}$ is the state vector. The first five state variables are, respectively, the generator deflection, the drive-train torsional deflection perturbation, and the flap displacement perturbations of three blades. The remaining five state variables are the corresponding velocities. $\mathbf{A}, \mathbf{B}, \mathbf{C}$, and $\mathbf{D}$ are the state matrix, the control input matrix, the output matrix, and the control input transmission matrix. $\mathbf{B}_{d}$ and $\mathbf{D}_{d}$ are the wind disturbance input matrix and the wind disturbance input matrix. $\mathbf{u}$ is the control input (i.e., perturbed blade collective pitch angle), $\mathbf{u}_{d}$ is the disturbance input (i.e., perturbed wind speed), and $\mathbf{y}$ is the output. The design point for linearization is chosen to be in Region 3. An operating point 
183 with wind speed $v=15 \mathrm{~m} / \mathrm{s}$, pitch angle $\theta=10.45 \mathrm{deg}$, and rotor speed $\omega_{r}=12.1 \mathrm{rpm}$ is used in the subsequent control investigations.

\section{Control Syntheses}

In this section we first outline a GSPI controller that is one of the baselines to illustrate the mathematical background and also the challenge, and then present the formulation of the proposed model reference adaptive control with disturbance accommodation. For these controllers, we assume the filtered generator speed measurement is the only input and the controllers provide the collective pitch command.

\subsection{Baseline gain scheduled proportional integral control and generator torque control}

One baseline controller used for comparison in this research is the gain scheduled proportional integral control (GSPI) originally developed by Jonkman et al [2]. The conventional approach to controlling power output involves two independent control loops, i.e., the generator torque control and the full-span rotor collective blade pitch control. The purpose of blade pitch control is to regulate the generator speed to avoid excessive structural loads at above-rated wind speed. The generator torque control aims at achieving the maximum power capture in various regions.

The form of GSPI can be written as

$$
\Delta \theta=G S(\theta)\left(K_{P} \Delta \omega+K_{I} \int_{0}^{t} \Delta \omega\right)
$$

where $\Delta \theta$ is the small perturbation of blade pitch angle around the operating point, and $\Delta \omega$ is the error between measured generator speed and the rated set point value. $K_{P}$ and $K_{I}$ are first calculated under the initial operating point. The gain correction factor $G S(\theta)$ is a function of the blade pitch angle to regulate the gains under different operating conditions [2],

where $\theta$ is the blade pitch angle, and $\theta_{k}$ is the blade pitch angle at which the pitch sensitivity value is doubled from its value at the rated operating point. The pitch sensitivity refers to the sensitivity of aerodynamic power to the rotor collective blade pitch angle.

As mentioned, another component of wind turbine control is the generator torque control. In Region

211 whereas the pitch angle is kept constant zero. Region $2 \frac{1}{2}$ is a linear transition to capture the maximum 212 power when the generator speed approaches the rated-speed. According to [2], the baseline torque control can be formulated as 


$$
\tau=\left\{\begin{array}{cc}
0 & \text { Region 1 } \\
k \omega^{2} & \text { Region 2 } \\
\tau_{1}+\frac{\tau_{\text {rated }}-\tau_{1}}{\omega_{\text {rated }}-\omega_{1}}\left(\omega-\omega_{1}\right) & \text { Region 2 } \frac{1}{2} \\
\tau_{\text {rated }} & \text { Region 3 }
\end{array}\right.
$$

215 where $\omega$ is the generator speed, $k$ is an optimal constant, i.e., $0.0255764 \mathrm{Nm} / \mathrm{rpm}^{2}$ for this benchmark

216 wind turbine. The transitional generator speed $\omega_{1}$ is $1,161.963 \mathrm{rpm}$ (i.e., $99 \%$ of the rated-speed), the

217 generator rated-speed $\omega_{\text {rated }}$ is $1173.7 \mathrm{rpm}$, the rated generator torque $\tau_{\text {rated }}$ is $43,093.55 \mathrm{Nm}$, and $\tau_{1}$ is

$21843,092.38 \mathrm{Nm}$ to yield the generator-slip percentage constant of $10 \%$.

219 It is worth noting that GSPI is designed for generator speed tracking in the above-rated region, which 220 may indeed cause large fluctuation in component loads. In addition, the proportional and integral gains 221 are tuned without considering the possible uncertainties in the plant. Consequently, it may not work well 222 when inherent and external uncertainties exist.

\subsection{Model reference adaptive control with disturbance accommodation}

The life span of wind turbines is expected to be 20 years or longer. In reality, wind turbines are often subjected to harsh environment with highly turbulent wind field. There is a large fluctuation in aerodynamic forces and moments to the blade. Such situation, if not handled properly, may lead to speed at the rated value and reduce the oscillation. Thus an intelligent control system is desired to ensure both the near-term performance (constant speed) and long-term reliability (less failure).

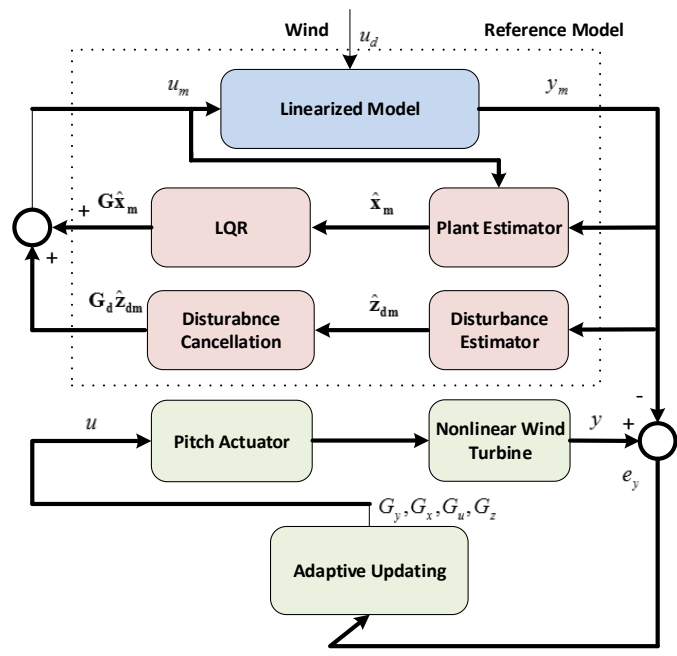

233 Figure 2. Direct model reference adaptive control approach with a disturbance accommodation controller (DAC). 
The model fidelity of the plant is essential for all control systems. In wind turbines, nevertheless, the system parameters are usually not completely known, due to, for example, the inherent nonlinearities of the model, unmodeled modes, manufacturing and assemblage tolerances, and external operating uncertainties. One potential solution is to use an adaptive control approach which can deal with various uncertainties by online updating parameters to force the error between reference and plant output to approach zero. Here in this research we adopt the direct model reference adaptive control approach with a disturbance accommodation controller (DAC) (Figure 2) [33]. There are two parts in this augmented controller. One is the reference model which is chosen as the DAC scheme. The other is the adaptive part, where the algorithms can adapt itself to the internal and external uncertainties. These two parts will

244 be discussed as follows.

\section{Reference model formulation with disturbance accommodation}

The concept of Disturbance Accommodating Control (DAC) was originally proposed by Johnson [31], and Balas et al [32] further extended the DAC concept to large-scale horizontal axis wind turbines. In the adaptive control to be developed in this research, we employ the DAC strategy to formulate the reference model. As the error between the reference and plant output approaches zero, the wind disturbance effect is reduced and the component loads are mitigated. Furthermore, an optimal control inner loop is embedded in the reference model in order to realize the trade-off between the load mitigation and generator speed tracking.

Recall the linearized state-space equation of the system, Equation (10). In DAC, we assume that wind disturbance is the variance from the wind speed at the operating point and has a known waveform but unknown amplitude. Specifically, we can model it as step disturbance [3, 4, 7, 8], where the amplitude of wind speed changes from one to another within a relatively short sampling interval. The wind disturbance is denoted as $\mathbf{u}_{d}$, and is characterized by the following disturbance wave generator,

259 For the step disturbance, $\mathbf{F}$ and $\boldsymbol{\Theta}$ are assumed to be known as

$$
\mathbf{F}=0, \quad \boldsymbol{\Theta}=1
$$

261 In Equation (10b), $\mathbf{D}$ and $\mathbf{D}_{d}$ are both equal to zero according to the FAST linearization. When we give a 262 bounded control input $\mathbf{u}_{m}$ (i.e., blade pitch angle signal) to the linearized model and maintain the stability 263 of the closed-loop system (i.e., the eigenvalues of the closed-loop system all having negative real parts), 264 the closed-loop DAC system, which is used as the reference model in the proposed adaptive control 265 strategy, can be expressed as 


$$
\begin{aligned}
\dot{\mathbf{x}}_{m} & =\mathbf{A}_{m} \mathbf{x}_{m}+\mathbf{B}_{m} \mathbf{u}_{m}+\mathbf{B}_{d m} \mathbf{u}_{d m} \\
\mathbf{y}_{m} & =\mathbf{C}_{m} \mathbf{x}_{m}
\end{aligned}
$$

267 where $\mathbf{A}_{m}, \mathbf{B}_{m}, \mathbf{B}_{d m}$, and $\mathbf{C}_{m}$ are the state, input, disturbance input, and output matrices of the linearized model. In DAC, the control law is expressed as combination of full state feedback (which is intended to take load mitigation into consideration) and disturbance state feedback to reject disturbances,

$$
\mathbf{u}_{m}=\mathbf{G} \mathbf{x}_{m}+\mathbf{G}_{d} \mathbf{z}_{d m}
$$

where $\mathbf{G}$ is the state gain and $\mathbf{G}_{d}$ is the disturbance state gain. We then have

$$
\dot{\mathbf{x}}_{m}=\left(\mathbf{A}_{m}+\mathbf{B}_{m} \mathbf{G}_{m}\right) \mathbf{x}_{m}+\left(\mathbf{B}_{m} \mathbf{G}_{d}+\mathbf{B}_{d m} \boldsymbol{\Theta}\right) \mathbf{z}_{d m}
$$

As mentioned, the first term at the right hand side of Equation (18) is related to the regulation of generator speed with load mitigation being considered. As such, $\mathbf{G}$ can be obtained by Linear Quadratic Regulator (LQR) approach, i.e., minimizing the quadratic performance index [38]:

$$
J=\frac{1}{2} \int_{0}^{\infty}\left(\mathbf{x}_{m}(\mathbf{t})^{T} \mathbf{Q} \mathbf{x}_{m}(\mathbf{t})+\mathbf{u}_{m}(t)^{T} \mathbf{R} \mathbf{u}_{m}(t)\right) d t
$$

where $\mathbf{Q}$ is a positive-semidefinite, real, symmetric matrix and $\mathbf{R}$ is a positive-definite, real, symmetric matrix. For the NREL 5-MW benchmark wind turbine, the linearized system described by Equation (10) is actually not state controllable because the rank of its controllability matrix is less than the order of the system. Therefore, further reduction of the system is necessary in order to allow arbitrary selection of system poles to enhance damping and improve system responses (with G) [3]. Here we reduce the original six states (displacements and velocities) for flapwise mode of three blades to one symmetric displacement state and one symmetric velocity state. Meanwhile, as the only available measurement is generator speed, the corresponding system is not observable (i.e., the rank of the observability matrix is less than the order of the system). We eliminate the state for generator deflection mode and only reserve generator speed state to enable the placement of the poles of the estimators which will be discussed later.

After the reduction of the linearized model, we can use Equations (17), (18) and (19) to facilitate the design of reference model with desired response. The diagonal elements in $\mathbf{Q}$ and $\mathbf{R}$ need to be adjusted properly to move the poles further to the left in the complex plane [23]. In some scenarios, the improvements of flapwise mode performance may deteriorate the generator mode response. Thus we should carefully choose $\mathbf{Q}$ and $\mathbf{R}$ to obtain an optimal trade-off between speed regulation and flapwise displacement response. An illustration will be presented in the case studies section.

The second term at the right hand side of Equation (18) concerns the disturbance. To mitigate the effect of disturbance, we can generally choose $\mathbf{G}_{d}$ in such a manner that the coefficient matrix of disturbance $\mathbf{B G}_{d}+\mathbf{B}_{d} \boldsymbol{\Theta}$ in Equation (18) is equal to zero, i.e., to realize disturbance cancellation. In 
most cases, this matrix does not have full rank and is ill-conditioned. In those cases, we can opt to minimizing its $L_{2}$ norm $\left\|\mathbf{B G}_{d}+\mathbf{B}_{d} \boldsymbol{\Theta}\right\|$ and obtain

$$
\mathbf{G}_{d}=-\left(\mathbf{B}_{m}^{T} \mathbf{B}_{m} \mathbf{B}_{m}^{T}\right)^{-1} \mathbf{B}_{d m}
$$

As the only measurement considered to be available is the generator speed, here state estimator is used to predict the unmeasured states. The plant state and output estimator are given as

$$
\begin{aligned}
\dot{\hat{\mathbf{x}}}_{m} & =\mathbf{A}_{m} \hat{\mathbf{x}}_{m}+\mathbf{B}_{m} \mathbf{u}_{m}+\mathbf{K}_{1}(\mathbf{y}-\hat{\mathbf{y}})+\mathbf{B}_{d m} \hat{\mathbf{u}}_{d m} \\
\hat{\mathbf{y}}_{m} & =\mathbf{C} \hat{\mathbf{x}}_{m}
\end{aligned}
$$

where $\hat{\mathbf{x}}_{m}, \hat{\mathbf{u}}_{d m}$, and $\hat{\mathbf{y}}$ are the estimates of $\mathbf{x}_{m}, \mathbf{u}_{d m}$ and $\mathbf{y}$. The disturbance state estimator is used to predict the unknown wind disturbance,

$$
\begin{aligned}
& \hat{\mathbf{u}}_{d}=\boldsymbol{\theta} \hat{\mathbf{z}}_{d} \\
& \dot{\hat{\mathbf{z}}}_{d}=\mathbf{F} \hat{\mathbf{z}}_{d}+\mathbf{K}_{2}(\mathbf{y}-\hat{\mathbf{y}})
\end{aligned}
$$

where $\hat{\mathbf{u}}_{d}$ and $\hat{\mathbf{z}}_{d}$ are the estimates of $\mathbf{u}_{d}$ and $\mathbf{z}_{d}$. Recall Equation (10). These two estimators can be joined as an augmented state estimator form. $\mathbf{K}_{1}$ and $\mathbf{K}_{2}$ are adjusted by pole placement such that the estimator has acceptable transient behavior and accuracy.

\section{Adaptive algorithm development}

The formulation of the DAC-type reference model, as explained in the preceding subsection, enables us to reach a trade-off by balancing load mitigation and speed regulation while reducing the disturbance effect. DAC controller, on the other hand, is not designed to be robust and it may be sensitive to errors in the turbine model. As shown in Figure 2, the second part of the proposed adaptive control scheme is the adaptation which allows us to take uncertainties into consideration. The uncertainties include 1) those caused by the nonlinear aerodynamic loads on the turbine, 2) varying wind speed, and 3) unmodeled dynamics.

For adaptive algorithm formulation, we assume the actual wind turbine is a linear, time-invariant, and finite dimensional plant shown as follows,

$$
\begin{aligned}
\dot{\mathbf{x}}_{p} & =\mathbf{A} \mathbf{x}_{p}+\mathbf{B} \mathbf{u}_{p}+\mathbf{B}_{d} \mathbf{u}_{d} \\
\mathbf{y}_{p} & =\mathbf{C} \mathbf{x}_{p}
\end{aligned}
$$

where $\mathbf{x}_{p}$ is the plant state vector, $\mathbf{u}_{p}$ is the plant input vector, and $\mathbf{y}_{p}$ is the plant output vector. In this research, the input is the collective pitch angle, and the output is the generator speed. It is worth noting that, in simulation, we will still employ the nonlinear NREL 5-MW benchmark as our actual plant. This proposed linearized model is only adopted for theoretical analysis of the adaptive control.

The error between the reference output $\mathbf{y}_{\mathbf{m}}$ and the plant output $\mathbf{y}$ is defined as $\mathbf{e}_{\mathbf{y}}$, i.e., 
325 where $\mathbf{y}$ is the actual plant output, and $\mathbf{y}_{\mathbf{m}}$ is the reference output obtained by the closed-loop DAC applied in Equation (16). Here $\mathbf{y}$ and $\mathbf{y}_{\mathbf{m}}$ are both actually scalars, because the only available measurement is the generator speed. The reference signal is essentially the result of a trade-off between the generator speed and blade flapwise loads. The purpose of the adaptive algorithm is to force the actual plant output $\mathbf{y}$ to follow the reference output $\mathbf{y}_{m}$, i.e. $\lim _{t \rightarrow \infty} \mathbf{e}_{\mathbf{y}}=0$, by online updating the parameters at every sampling step with unknown or varied system dynamics or other specific uncertainties.

The general theory of model reference adaptive control and the associated stability analysis can be 332 found in [34]. Here we have

$$
\mathbf{u}=\mathbf{G}_{y} \mathbf{e}_{y}+\mathbf{G}_{x} \hat{\mathbf{x}}_{m}+\mathbf{G}_{u} \mathbf{u}_{m}+\mathbf{G}_{z} \hat{\mathbf{z}}_{d}
$$

334 Correspondingly, the adaptive gain laws are

$$
\dot{\mathbf{G}}_{y}=-\mathbf{K}_{y} \mathbf{e}_{y} \mathbf{e}_{y}^{T}, \quad \dot{\mathbf{G}}_{x}=-\mathbf{K}_{x} \mathbf{e}_{y} \hat{\mathbf{x}}_{m}^{T}
$$$$
\dot{\mathbf{G}}_{u}=-\mathbf{K}_{u} \mathbf{e}_{y} \mathbf{u}_{m}^{T}, \quad \dot{\mathbf{G}}_{z}=-\mathbf{K}_{z} \mathbf{e}_{y} \hat{\mathbf{z}}_{d}^{T}
$$

where $\mathbf{K}_{y}, \mathbf{K}_{x}, \mathbf{K}_{u}, \mathbf{K}_{z}$ can be arbitrary, positive-definite matrices. In order to guarantee the stability, we must have the following conditions satisfied $[5,26,34]$ :

1) All inputs to the reference model are bounded. In this research, the pitch angle input bound is guaranteed by the pitch angle limits (0-90 degree). The disturbance bound is also guaranteed since the wind turbine is stopped to avoid excessive loads when the wind speed exceeds the cutout value $(25 \mathrm{~m} / \mathrm{s})$.

2) The reference model (closed-loop DAC) described by Equation (18) is stable. In this research, all the eigenvalues of closed-loop system are placed in the left-half $s$-plane.

3) The system described by Equation (23) is Almost Strict Positive Real (ASPR). This is satisfied when the transfer function $\mathbf{C}_{p}\left(s \mathbf{I}-\mathbf{A}_{p}\right)^{-1} \mathbf{B}_{p}$ is Strictly Positive Real [5]. The linearized model has been examined at different operating points to validate this condition.

The selection of parameters in Equations (25) and (26) is based on the control objective which is to regulate the generator speed according to the closed-loop DAC output and achieve simultaneously load mitigation. Since we have considered the disturbance rejection in reference model by DAC approach, the gain $\mathbf{G}_{z}$ in Equation (25) is chosen to be 0. Our main task is to track the generator speed and we do not need to track the control input. Thus we can also set $\mathbf{G}_{u}$ to be 0 . Similarly, all the elements in matrix $\mathbf{G}_{x}$ 353 are chosen to be 0 except the one that corresponds to the generator speed state. Therefore, in Equation 
354 (26), the adaptive gains $\mathbf{K}_{u}$ and $\mathbf{K}_{z}$ are 0 . We can adjust $\mathbf{K}_{y}$ and $\mathbf{K}_{x}$ to achieve the desired generator 355 speed regulation and load mitigation effect.

Table 1. Wind file parameters.

\begin{tabular}{cccc}
\hline & Case 1 & Case 2 & Case 3 \\
\hline Mean wind speed $(\mathrm{m} / \mathrm{s})$ & 15 & 12 & 17 \\
Turbulence model & & IEC Kaimal spectral model \\
Turbulence intensity & & IEC category B (14\%) \\
Height of reference wind speed $(\mathrm{m})$ & & 90 \\
\hline
\end{tabular}

\section{Results and Discussions}

In this section, case analysis results based on the GSPI, DAC, and the proposed adaptive control algorithm are compared. The simulations on the NREL offshore 5-MW benchmark wind turbine are carried out by connecting FAST with the respective controllers in the Matlab/Simulink environment. The simulation duration is 600 seconds with an integration step size of 0.0125 second. As mentioned, the

363 model involves five DOFs including the first flapwise blade mode DOF of 3 blades, the generator DOF, 364 and the drivetrain torsional flexibility DOF. Aerodynamic forces and moments are calculated by using AeroDyn. Turbulent wind fields are generated by using TurbSim [35]. Table 1 lists all the simulation parameters used to obtain the wind fields. The mean wind speeds are set to be below, above and equal to the operating point value $(15 \mathrm{~m} / \mathrm{s})$, respectively, corresponding to three cases studied in this section. The Simulink model of the adaptive pitch controller is shown in Figure 3.

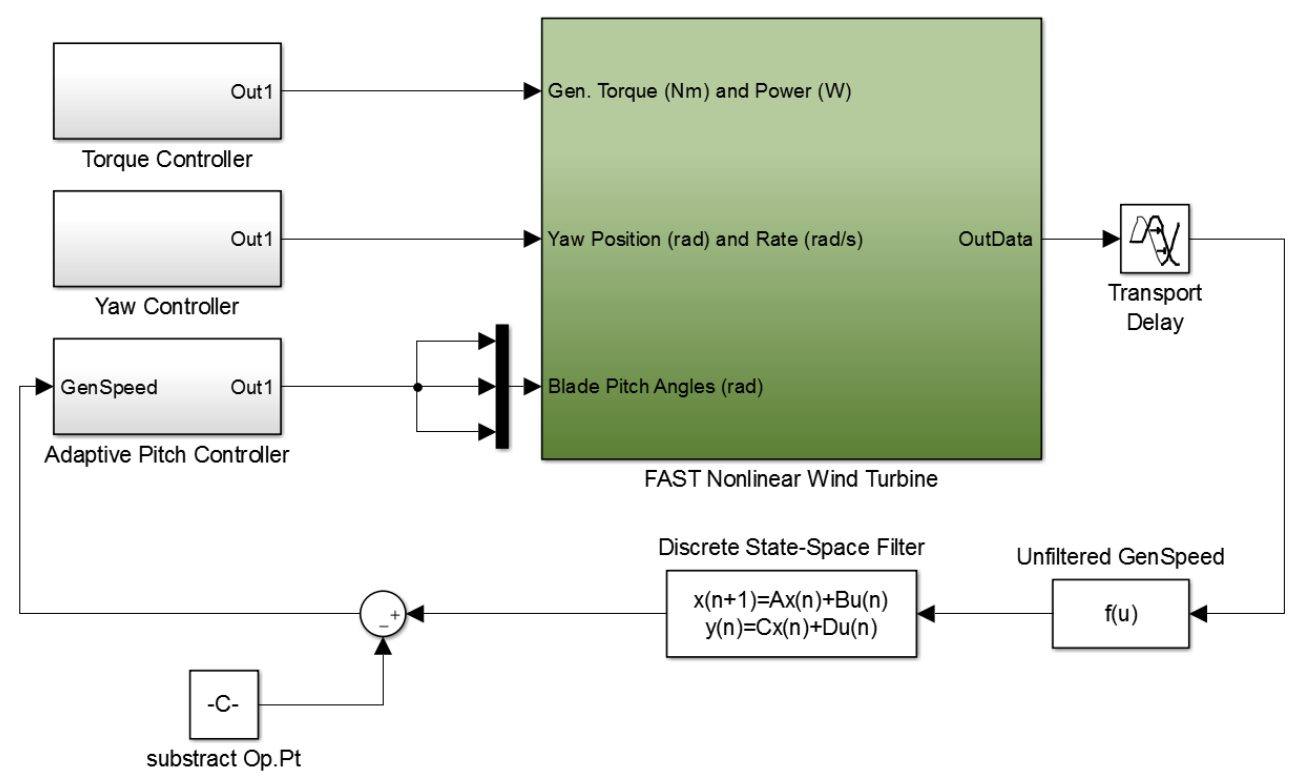

Figure 3. Controller block diagram. 


\subsection{Selection of parameters in closed-loop DAC used as reference model}

The design of closed-loop DAC is important, because it will be used as the reference model in the proposed adaptive control, and DAC will also be used for performance comparison. As indicated in Section 3.2, we should carefully choose the weighting matrices $\mathbf{Q}$ and $\mathbf{R}$ in Equation (19) to facilitate an optimal trade-off between speed regulation and flapwise displacement response. We may choose different $\mathbf{Q}$ and $\mathbf{R}$ combinations and examine the closed-loop poles. Here the open-loop poles are $-1.9010 \pm 13.892 i,-2.4642 \pm 3.9884 i$, and -0.4524 . The first pair of poles corresponds to the drive-train torsional mode, the second pair corresponds to the symmetric first flapwise blade mode, and the last pole corresponds to the generator mode. When we select, for example,

$$
\mathbf{R}=1, \quad \mathbf{Q}=\left[\begin{array}{ccccc}
10^{-5} & 0 & 0 & 0 & 0 \\
0 & 0.1 & 0 & 0 & 0 \\
0 & 0 & 0.06 & 0 & 0 \\
0 & 0 & 0 & 100 & 0 \\
0 & 0 & 0 & 0 & 10^{-3}
\end{array}\right]
$$

we can obtain the closed-loop poles as $-2.5578 \pm 13.6131 i,-13.5563 \pm 3.1939 i,-0.4180$. The damping in the flap mode (i.e., the second pair) is increased as the corresponding poles are moved from $-2.4642 \pm 3.9884 i$ to $-13.5563 \pm 3.1939 i$. However, at the same time, the damping in the generator mode is reduced as the corresponding pole is moved from -0.4524 to -0.4180 . Clearly, a trade-off exists between the flapwise mode and generator mode. Alternatively, we may select

$$
\mathbf{R}=1, \quad \mathbf{Q}=\left[\begin{array}{ccccc}
10^{6} & 0 & 0 & 0 & 0 \\
0 & 10^{-2} & 0 & 0 & 0 \\
0 & 0 & 0.8 & 0 & 0 \\
0 & 0 & 0 & 0.01 & 0 \\
0 & 0 & 0 & 0 & 10^{-4}
\end{array}\right]
$$

The closed loop poles now become $-14.0626 \pm 20.3352 i,-6.0725 \pm 2.2044 i$, and -2.2319 , indicating both the flapwise mode and generator mode can be enhanced after careful selection of $\mathbf{Q}$ and $\mathbf{R}$. The corresponding gain matrix $\mathbf{G}$ is [-802.7443,0.4439,21.7998,19.0430,0.0735]. This result is adopted in the reference model for the following three case studies.

\subsection{Results of GSPI, DAC and adaptive control under different turbulent wind fields}

The DAC and the adaptive controller are simulated in all three abovementioned (below-rated, rated, above-rated) wind fields, and compared to the baseline GSPI controller. The parameters of the controllers involved in the case studies are summarized in Table 2. In order to compare these three different 
controllers, four performance indices are analyzed: Root Mean Square (RMS) error of generator speed, mean power average, blade root flapwise moment DEL, and maximum flapwise moment. Here DEL refers to the fatigue damage equivalent load (DEL), which serves as an important metric for comparing fatigue loads across the entire spectrum of turbulent wind files. The equivalent fatigue damage is represented by a constant load and calculated by MLife [36]. MLife is a post-processing code developed by NREL to assess fatigue according to rainflow counting algorithm [37]. In high-cycle fatigue situations, materials performance is usually characterized by an S-N curve (i.e., Wöhler curve). Here the S-N slope of 10 is used which is typical for composite materials (blade).

Table 2. Parameters of controllers.

\begin{tabular}{ccc}
\hline$G S(\theta)$ & Gain correction factor & $\frac{1}{1+\theta / 6.302336}$ \\
$K_{P}$ & Proportional gain & 0.01882681 \\
$K_{I}$ & Integral gain & 0.008068634 \\
$\mathbf{R}$ & Weighting matrix & 1 \\
$\mathbf{Q}$ & Weighting matrix & $\operatorname{diag}\left(\left[10^{6}, 10^{-2}, 0.8,0.01,10^{-4}\right]\right)$ \\
$\mathbf{G}$ & State gain & 0.0264 \\
$\mathbf{G}_{d}$ & Disturbance state gain & $10^{-7}$ \\
$\mathbf{K}_{y}$ & Adaptive gain & $10^{-10}$ \\
$\mathbf{K}_{x}$ & Adaptive gain &
\end{tabular}

410 Case 1 concerns the results under turbulent $15 \mathrm{~m} / \mathrm{s}$ wind field. $15 \mathrm{~m} / \mathrm{s}$ is the mean speed of wind 411 distribution from 0 to $600 \mathrm{~s}$. The wind file, generator speed, pitch angle and blade root flapwise moment 412 are shown in Figures 4(a) to 4(d), respectively. From Figure 4(b) we can see that there is less fluctuation 413 of generator speed under adaptive control than that under DAC. The pitch angle change rate is smaller 414 under adaptive control than that under DAC or GSPI, as shown in Figure 4(c). It is observed that the 415 GSPI yields higher flapwise root moment from $360 \mathrm{~s}$ to $480 \mathrm{~s}$, compared with DAC and adaptive control, 416 as shown in Figure 4(d). The overall performances are compared in Figure 5, where all performance 417 indices are normalized with respect to those obtained based on GSPI. It can be seen that the adaptive 418 controller reduces the flapwise moment DEL by $9 \%$ which is similar to DAC controller. The normalized 419 generator speed errors of GSPI, DAC and adaptive control are 0.1693, 0.2960, and 0.1727, respectively. 
The DAC controller exhibits a much larger error than the adaptive controller. The average power output of the adaptive controller is slightly less than those of GSPI and DAC. The extreme flapwise moment is 422 decreased about $11 \%$ in DAC and adaptive control. Therefore, at operating point, the flapwise fatigue 423 can be reduced by adaptive controller, although the generator speed regulation is not as good as GSPI 424 since GSPI is only designed for speed regulation without consideration of load mitigation.

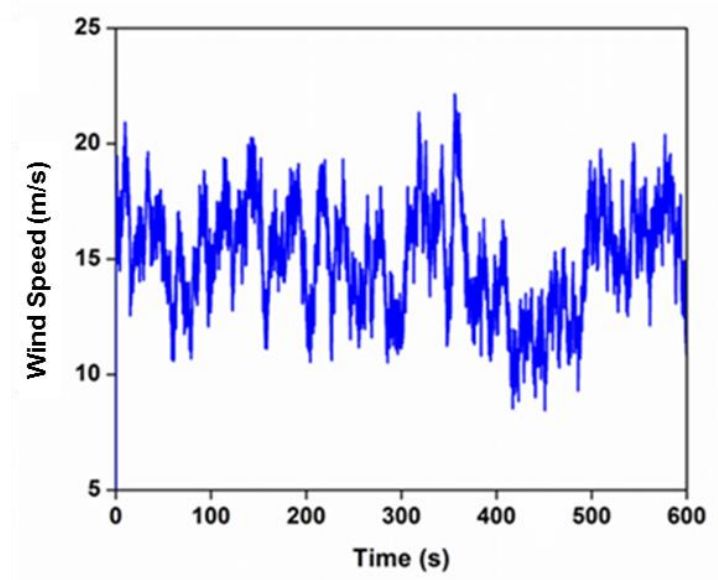

(a)

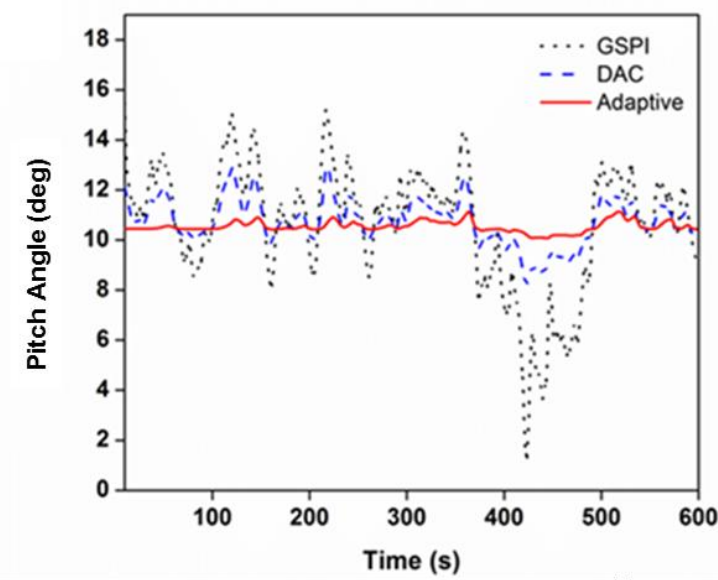

(c)

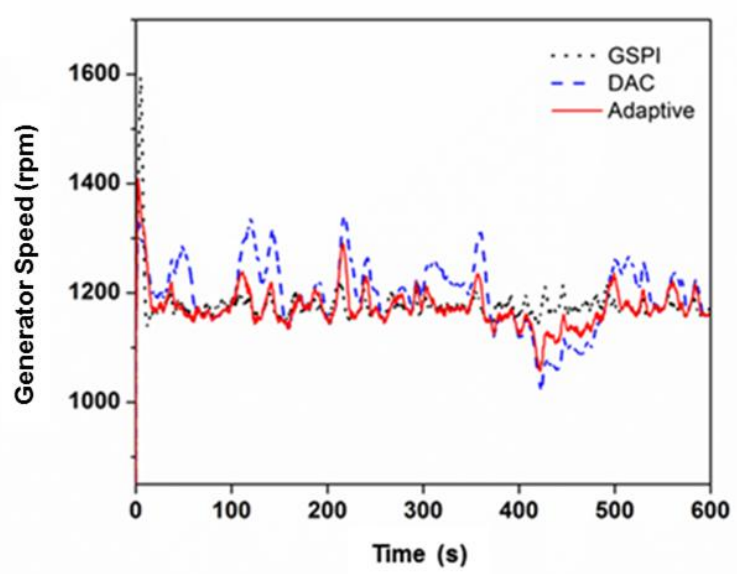

(b)

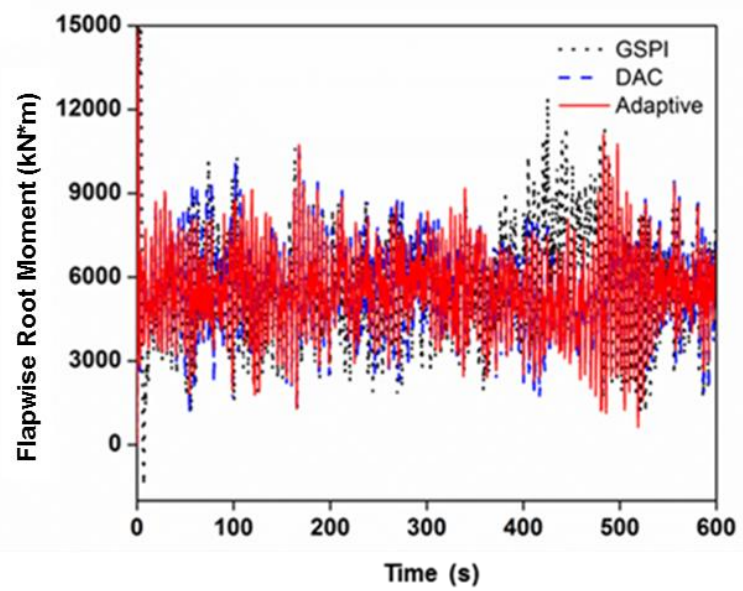

(d)
426

427 428 429

Figure 4. Time-domain performance comparison of GSPI, DAC, and adaptive control under $15 \mathrm{~m} / \mathrm{s}$ turbulent field. (a) Wind speed; (b) Generator speed; (c) Pitch angle; and (d) Flapwise root moment. 


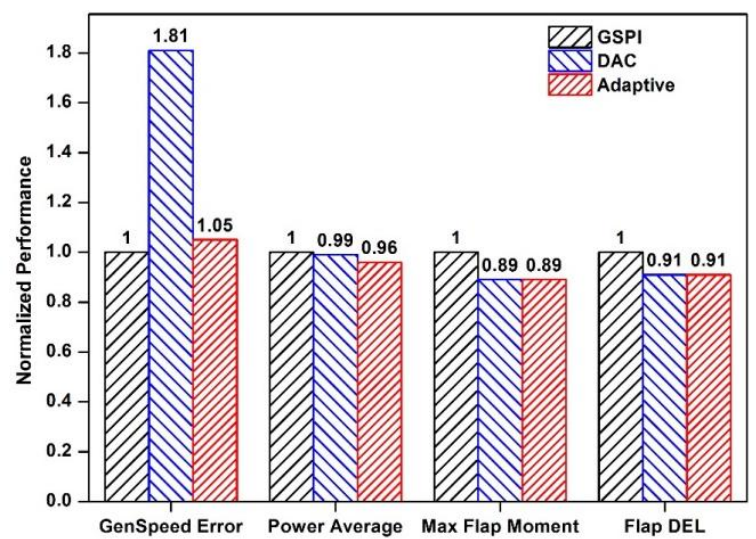

Figure 5. Performance comparison of GSPI, DAC and adaptive control under $15 \mathrm{~m} / \mathrm{s}$ turbulent field.

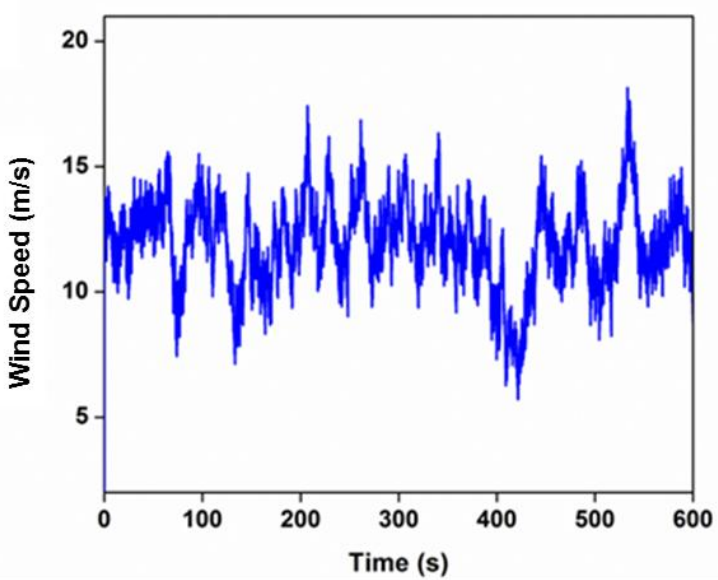

(a)

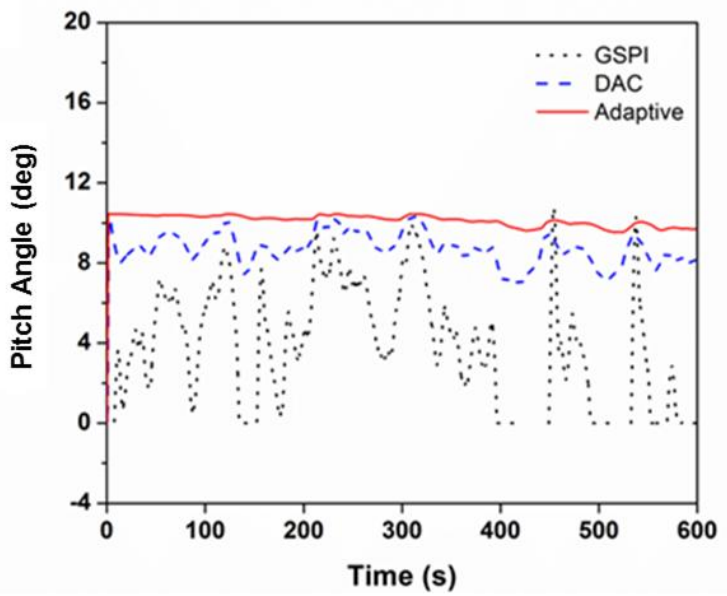

(c)

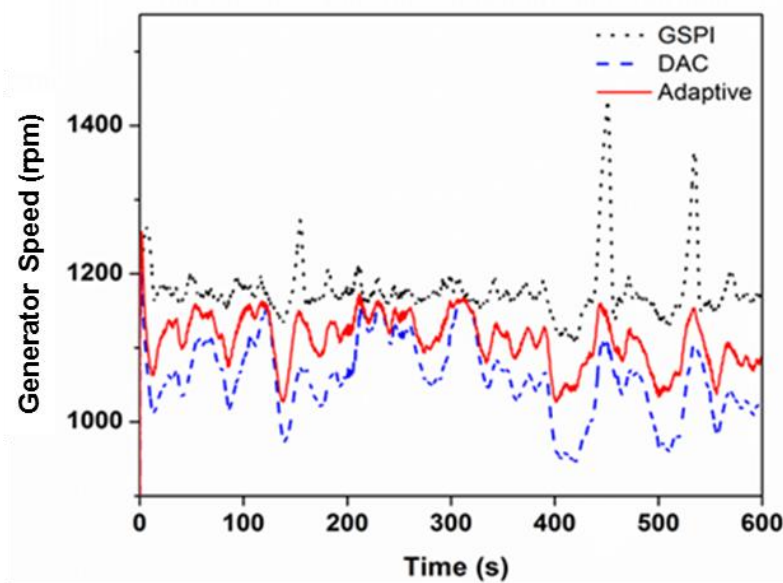

(b)

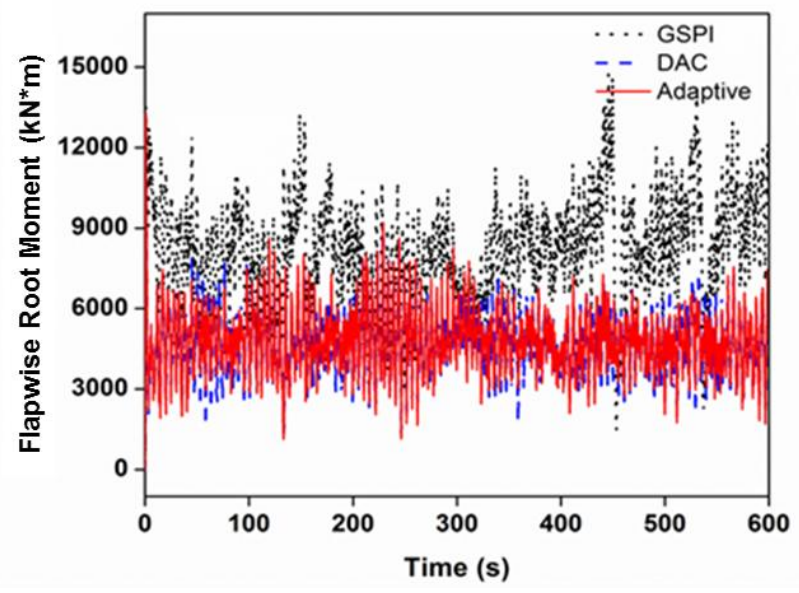

(d)

Figure 6. Time-domain performance comparison of GSPI, DAC, and adaptive control under $12 \mathrm{~m} / \mathrm{s}$ turbulent field. (a) Wind speed; (b) Generator speed; (c) Pitch angle; and (d) Flapwise root moment. 
For the situation where the wind speed is below the operating point, the turbulent wind field with mean wind speed $12 \mathrm{~m} / \mathrm{s}$ is chosen as Case 2. This wind file covers the switch region between Region 2

440 and Region 3 (since the rated wind speed is $11.4 \mathrm{~m} / \mathrm{s}$ for this $5-\mathrm{MW}$ turbine). The parameters of DAC 441 controller and adaptive controller are kept the same as those used in Case 1. The wind file, generator 442 speed, pitch angle and blade root flapwise moment are shown in Figures 6(a) to 6(d), respectively. GSPI 443 yields the highest activity of the pitch actuator, as shown in Figure 6(c). The overall value of flapwise 444 root moment is higher under GSPI than those under DAC and adaptive controller, as shown in Figure 6(d). 445 Therefore, when pitch angle is adjusted rapidly to maintain constant generator speed, it will cause large 446 oscillation in blade flapwise deflection. The normalized performances are compared in Figure 7. Similar 447 to DAC, the adaptive controller reduces the flapwise moment DEL by $38 \%$ as compared to the baseline 448 GSPI. However, as a trade-off, the power output exhibits a decrease of $36 \%$ (under DAC) and $25 \%$ 449 (under adaptive control), respectively, as compared to that of GSPI. The normalized generator speed 450 errors of three controllers are $0.1822,0.5740$, and 0.3316 , respectively. The maximum flapwise moments are also reduced by $10 \%$ under DAC and $9 \%$ under adaptive control.

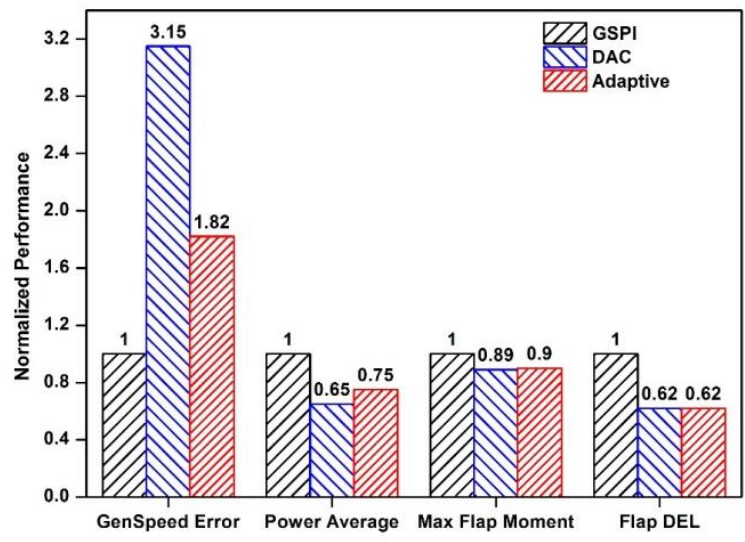




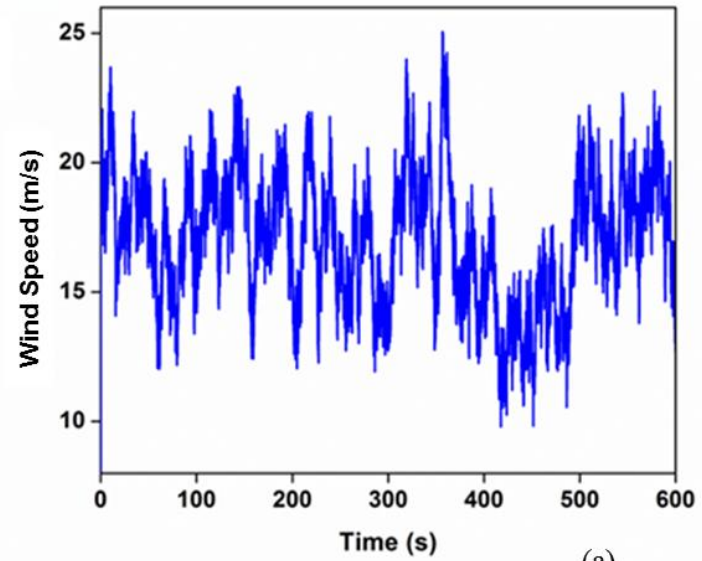

(a)

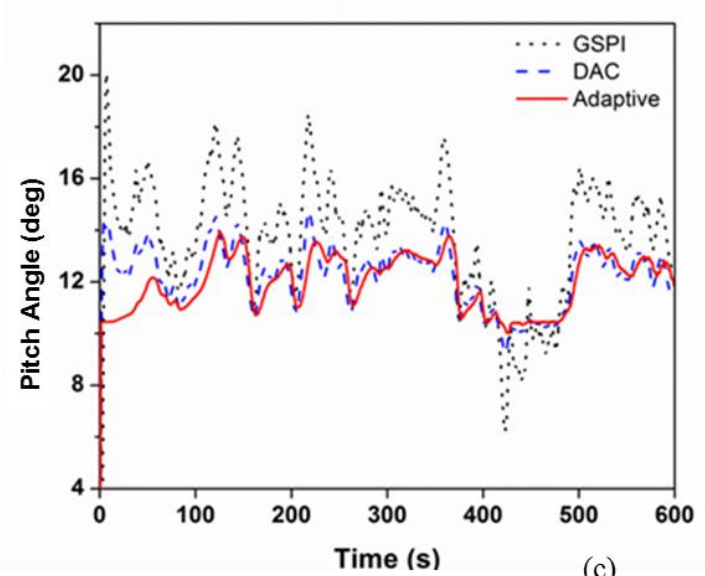

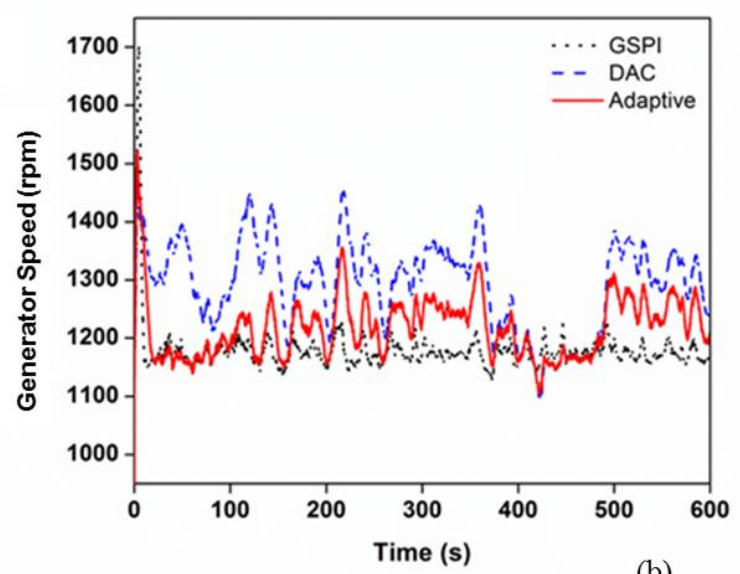

(b)

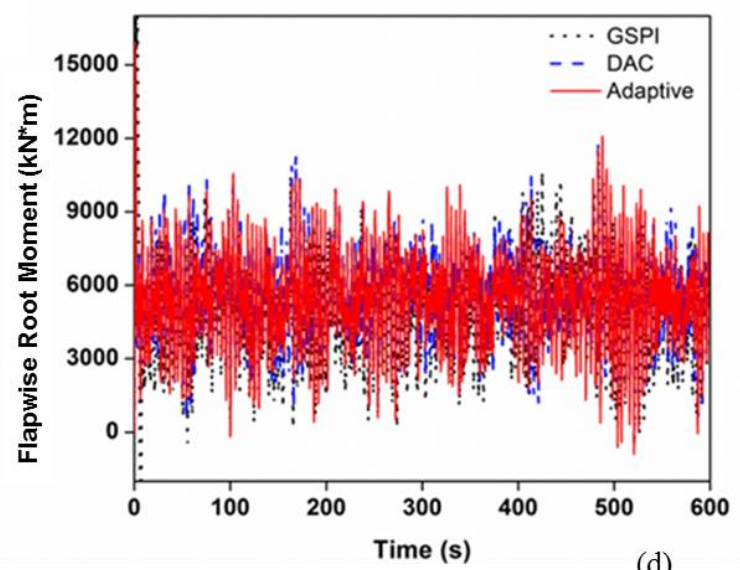

(d)
456

457

458

459

Figure 8. Time-domain performance comparison of GSPI, DAC, and adaptive control under $17 \mathrm{~m} / \mathrm{s}$ turbulent field. (a) Wind speed; (b) Generator speed; (c) Pitch angle; and (d) Flapwise root moment.

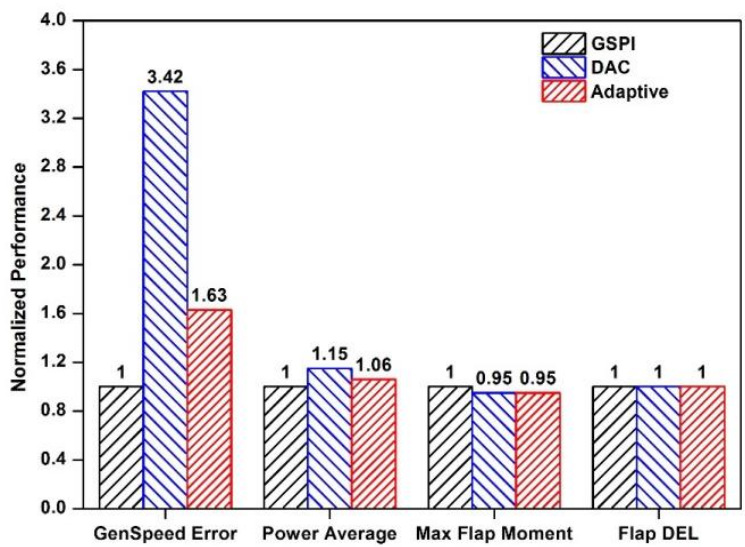

Figure 9. Performance comparison of GSPI, DAC and adaptive control under $17 \mathrm{~m} / \mathrm{s}$ turbulent field. 


\section{Case 3 results, under turbulent $17 \mathrm{~m} / \mathrm{s}$ wind field}

In Case 3 we consider turbulent $17 \mathrm{~m} / \mathrm{s}$ wind field. The wind file, generator speed, pitch angle and blade root flapwise moment are shown in Figures 8(a) to 8(d), respectively. The curve of generator speed under adaptive control is generally lower than the curve under DAC and higher than the curve under GSPI, as shown in Figure 8(b). The pitch angle curve under adaptive controller is very close to that under DAC, as shown in Figure 8(c). The flapwise root moment trends are shown in Figure 8(d), where three curves generally overlap. The normalized performance comparison is given in Figure 9. When the wind speed is above the operating point, the flapwise moment DEL values of three controllers are nearly the same while the extreme moment is decreased by $5 \%$ under DAC and adaptive control. This can be ascribed to the fact that the mean wind speed in Case 3 is far away from the operating point. GSPI still shows better ability to regulate the generator speed, and the RMS errors are $0.1964,0.6513$, and 0.3217 , respectively. Because of the larger wind speed, the average power output increases by $15 \%$ (under DAC) and 6\% (under adaptive), respectively, compared to that of GSPI. Therefore, in the above-rated region, the load mitigation performance of both DAC and adaptive control is still effective, and the adaptive control leads to better speed regulation than DAC as well as increased average power than both GSPI and DAC.

\subsection{Uncertainties analysis}

The performance improvement and robustness of the adaptive controller are demonstrated in the preceding section under different turbulent wind fields. Here we will further investigate the effect of inherent structural uncertainty of wind turbine to the controllers. Wind turbine operates in a very complicated environment with many sources of uncertainties such as potential blade damage and mass imbalance caused by rain and ice. Uncertainties may also be caused by manufacturing tolerance and inservice degradation. The benchmark 5-MW wind turbine blade has 49 elements with individual structural and aerodynamic properties defined by NREL [29]. Each element has different blade properties, i.e. aerodynamic center, structural twist angle, mass density, flapwise and edgewise stiffness. In this research Latin Hypercube Sampling is adopted to generate blade uncertainty which is used to assess the controller performances. For $n$ set of input stiffness values of blade elements $\Delta \mathbf{K}=\left[\Delta \mathbf{K}_{1}, \Delta \mathbf{K}_{2}, \cdots \Delta \mathbf{K}_{n}\right]$, the distribution of the corresponding inputs is assumed to be a multivariate Gaussian distribution. The mean function $\mu\left(\Delta \mathbf{K}_{i}\right)$ and the covariance function $\Sigma\left(\Delta \mathbf{K}_{i}, \Delta \mathbf{K}_{j}\right)$ are pre-specified. In addition, we assume $\Delta \mathbf{K}_{i}$ and $\Delta \mathbf{K}_{j}$ are independent of each other. Here we let the mean value of the stiffness uncertainty be -0.05 (i.e., $5 \%$ mean reduction, possibly caused by minor damage), and let the variance be $10^{-5}$. 20 samples of stiffness uncertainty are generated and injected into the analysis. For each sample, FAST 
497 linearization is utilized to obtain the new stiffness matrix $\tilde{\mathbf{K}}$, which is different from the original one. 498 One example is shown in Appendix. The mass matrix $\tilde{\mathbf{M}}$, the damping matrix $\tilde{\mathbf{C}}$, the wind input matrix $499 \tilde{\mathbf{F}}$ and the wind input disturbance matrix $\tilde{\mathbf{F}}_{d}$ all remain to be very close to the nominal values. The state 500 matrix is changed to $\tilde{\mathbf{A}}$, while other matrices $\mathbf{B}, \mathbf{B}_{d}$ and $\mathbf{C}$ remain unchanged.
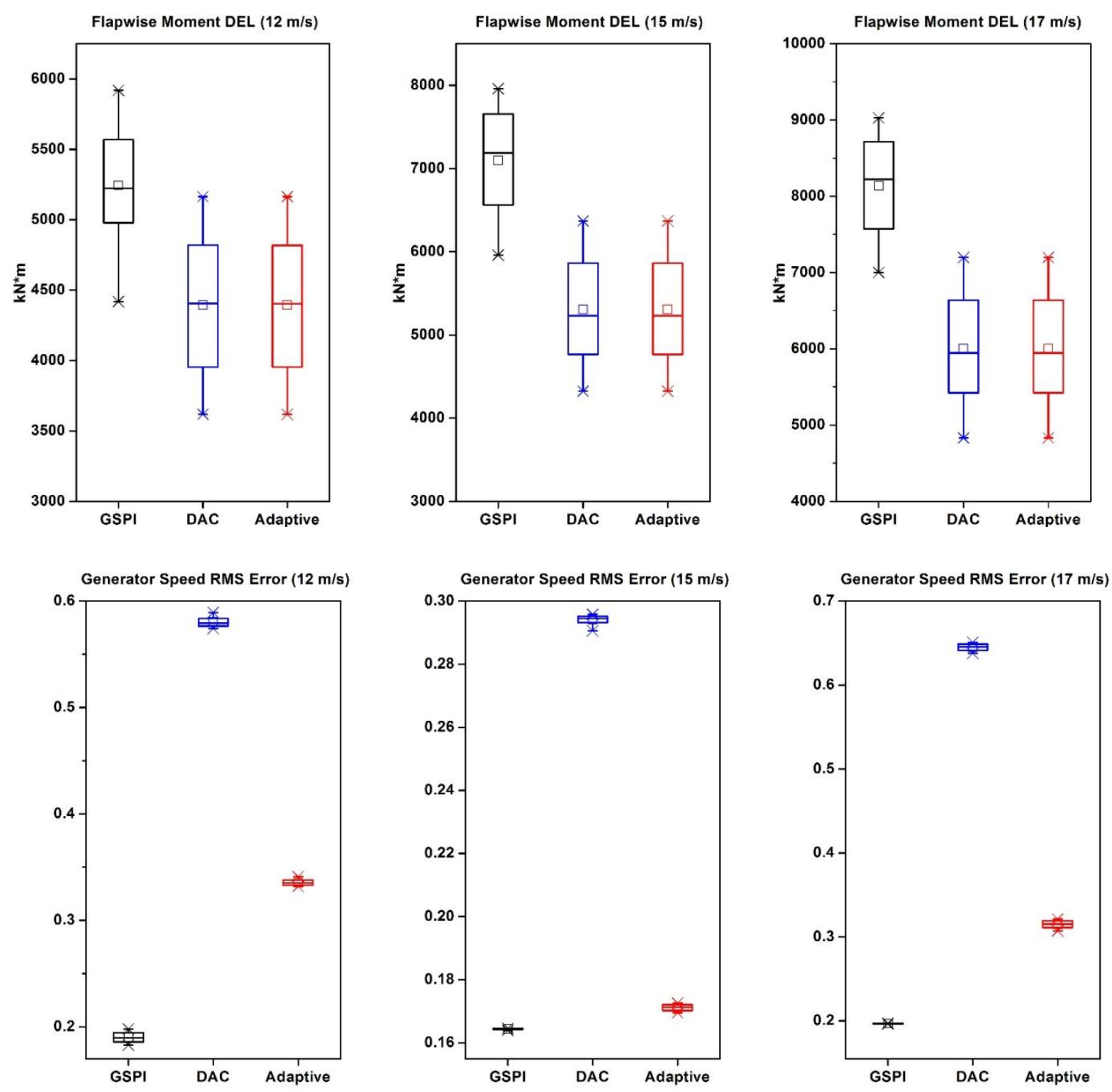

502 Figure 10. A summary of the flapwise moment DEL and generator speed RMS error for 20 blade stiffness reduction sets under $12 \mathrm{~m} / \mathrm{s}, 15 \mathrm{~m} / \mathrm{s}$ and $17 \mathrm{~m} / \mathrm{s}$ turbulent fields. 
In GSPI control, the gain scheduled part is only designed to deal with the varying operating point and cannot deal with model uncertainty. The performance of GSPI will then be sensitive to state matrix change. In DAC approach, the wind disturbance $\mathbf{G}_{d}$ is not affected by the change of state matrix A while the response vector will be affected. Theoretically, the initial $\mathbf{G}$ (without the blade stiffness uncertainty) is not able to maintain the exact same performance of speed regulation and load mitigation. However, the gain $\mathbf{G}$ also possesses robustness. In practice, we still adopt the initial $\mathbf{G}$ to obtain the reference signal and examine the robustness of the DAC and the adaptive controller under structural uncertainty.

511 The results obtained under GSPI, DAC and adaptive control with the blade stiffness 512 uncertainty/reduction are shown in Figure 10, where box whisker plots for 20 different blade stiffness 513 files are provided. The flapwise moment DELs of both DAC and adaptive control exhibit a significant 514 decrease compared to those of GSPI. The flap DEL is decreased by $20 \%$ to $28 \%$ at $15 \mathrm{~m} / \mathrm{s}$. Similar trend 515 of DEL decrease of $21 \%$ to $23 \%$ and $21 \%$ to $31 \%$ are observed at $12 \mathrm{~m} / \mathrm{s}$ and $17 \mathrm{~m} / \mathrm{s}$ respectively under 516 DAC and adaptive control. We can then conclude that GSPI is more sensitive to model uncertainty than 517 DAC and adaptive control. In nominal condition without uncertainty, a reduction of 9\% in flap DEL is 518 achieved by both DAC and adaptive control as compared to GSPI. With uncertainty, the flap DEL 519 reductions by DAC and adaptive control have been increased to over $20 \%$ than GSPI. For generator 520 regulation, we can see from the 20 sets of results that DAC shows the largest variation and the generator 521 speed error of adaptive control is smaller than that of GSPI. GSPI still exhibits the best speed regulation 522 performance, primarily because it only tracks the reference value and does not contribute to load 523 mitigation. When uncertainty is present, DAC and adaptive control lead to much better performance as 524 compared to GSPI. Also, we can observe that all the absolute values of flap DEL with blade stiffness 525 uncertainty are increased compared to those in the nominal condition. On the other hand, the stiffness 526 uncertainty does not affect the generator speed error. The flap DEL values are increased when the mean 527 wind speed changes from $12 \mathrm{~m} / \mathrm{s}$ to $17 \mathrm{~m} / \mathrm{s}$ and thus the larger wind speed will lead to increased flap DEL.

\section{Concluding Remarks}

In this research an adaptive control with disturbance rejection and load mitigation capability is studied, aiming at improving the life span of wind turbines operating in high wind speeds. The proposed algorithm is applied to the NREL offshore 5-MW baseline wind turbine. It is identified that the load mitigation performances of the adaptive control and DAC are comparable which are both better than the

534 baseline GSPI. Furthermore, for generator speed regulation, adaptive control performs better than DAC. 535 With the possible existence of structural uncertainty such as stiffness reduction in wind turbine blades, 536 GSPI will be sensitive to model uncertainty. The adaptive control, on the other hand, can deal with such 537 uncertainty. The results indicate that adaptive control can both enhance the load mitigation over GSPI 
and improve speed regulation over DAC. The formulation developed in this research is general, and can be extended to mitigating loads on other components.

\section{Acknowledgment}

This research is supported by National Science Foundation under grant CMMI - 1300236.

\section{References}

[1] Pao, L.Y., and Johnson, K.E., 2009, "A tutorial on the dynamics and control of wind turbines and wind farms," American Control Conference, St. Louis, MO, June 10-12, pp. 2076-2089.

[2] Jonkman, J.M., Butterfield, S., Musial, W., and Scott, G., 2009, Definition of a 5-MW Reference Wind Turbine for Offshore System Development, Technical Report No. NREL/TP-500-38060, National Renewable Energy Laboratory, Golden, CO.

[3] Wright, A.D., 2004, Modern Control Design for Flexible Wind Turbines, Technical Report No. NREL/TP-500-35816, National Renewable Energy Laboratory, Golden, CO.

[4] Wright, A.D., and Balas, M.J., 2003, "Design of state-space-based control algorithms for wind turbine speed regulation,” Journal of Solar Energy Engineering, V125 (4), pp. 386-395.

[5] Frost, S.A., Balas, M.J., and Wright, A.D., 2009, "Direct adaptive control of a utility-scale wind turbine for speed regulation," International Journal of Robust and Nonlinear Control, V19 (1), pp. 59-71.

[6] Connor, B., Iyer, S.N., and Leithead, W.E., 1992, "Control of a horizontal axis wind turbine using H infinity control," Control Applications, First IEEE Conference on, Dayton, OH, September 13-16, pp.117-122.

[7] Stol, K.A., and Balas, M.J., 2003, "Periodic disturbance accommodating control for blade load mitigation in wind turbines,” Journal of Solar Energy Engineering, V125 (4), pp. 379-385.

[8] Hand, M.M., and Balas, M.J., 2007, "Blade load mitigation control design for a wind turbine operating in the path of vortices," Wind Energy, V10 (4), pp. 339-355.

[9] Soliman, M., Malik, O.P., and Westwick, D.T., 2010, "Multiple model MIMO predictive control for variable speed variable pitch wind turbines," American Control Conference, Baltimore, MD, June 30July 02, pp. 2778-2784.

[10] Bououden, S., Chadli, M., Filali, S., and El Hajjaji, A., 2012, "Fuzzy model based multivariable predictive control of a variable speed wind turbine: LMI approach,” Renewable Energy, V37 (1), pp. 434439.

[11] Sanchez, H., Escobet, T., Puig, V., and Odgaard, P.F., 2015, "Health-aware model predictive control of wind turbines using fatigue prognosis," IFAC-PapersOnLine, V48 (21), pp. 1363-1368. 
[12] Odgaard, P.F., Larsen, L.F., Wisniewski, R., and Hovgaard, T.G., 2016, “On using Pareto optimality

572 to tune a linear model predictive controller for wind turbines,” Renewable Energy, V87, pp. 884-891.

573 [13] Odgaard, P.F., 2015, "On usage of pareto curves to select wind turbine controller tunings to the wind

574 turbulence level,” European Control Conference, Linz, Austria, July 15-17 July, pp. 1534-1539.

575 [14] Odgaaard, P.F., Knudsen, T., Overgaard, A., Steffensen, H., and Jørgensen, M., 2015, “Importance

576 of dynamic inflow in model predictive control of wind turbines," IFAC-PapersOnLine, V48 (30), pp. 90-

$577 \quad 95$.

578 [15] Bossanyi, E., 2003, “Individual blade pitch control for load reduction,” Wind Energy, V6 (2), pp. 579 119-128.

580 [16] Bossanyi, E., 2005, "Further load reductions with individual pitch control," Wind Energy, V8 (4), pp. 581 481-485.

582 [17] Stol, K.A., Zhao, W., and Wright, A.D., 2006, "Individual blade pitch control for the controls 583 advanced research turbine (CART), ’ Journal of Solar Energy Engineering, V128 (4), pp. 498-505.

584 [18] Hassan, H.M., ElShafei, A.L., Farag, W.A., and Saad, M.S., 2012, "A robust LMI-based pitch 585 controller for large wind turbines," Renewable Energy, V44, pp. 63-71.

586 [19] Bottasso, C.L., Pizzinelli, P., Riboldi, C.E.D., and Tasca, L., 2014, "LiDAR-enabled model 587 predictive control of wind turbines with real-time capabilities," Renewable Energy, V71, pp. 442-452.

588 [20] Dunne, F., Pao, L.Y., Wright, A.D., Jonkman, B., and Kelley, N., 2011, "Adding feedforward blade 589 pitch control to standard feedback controllers for load mitigation in wind turbines," Mechatronics, V21 590 (4), pp. 682-690.

591 [21] Wang, N., Johnson, K.E., and Wright, A.D., 2012, "FX-RLS-based feedforward control for LIDAR592 enabled wind turbine load mitigation," IEEE Transactions on Control Systems Technology, V20 (5), pp. 593 1212-1222.

594 [22] Petrović, V., Jelavić, M., and Baotić, M., 2015, “Advanced control algorithms for reduction of wind 595 turbine structural loads," Renewable Energy, V76, pp. 418-431.

596 [23] Wright, A.D., and Fingersh, L.J, 2008, Advanced Control Design for Wind Turbines. Part I: Control 597 Design, Implementation, and Initial Tests, Technical Report No. NREL/TP-500-42437, National 598 Renewable Energy Laboratory, Golden, CO.

599 [24] Johnson, K.E. and Fingersh, L.J., 2008, “Adaptive pitch control of variable-speed wind turbines," 600 Journal of Solar Energy Engineering, V130 (3), pp. 031012.

601 [25] Balas, M., Magar, K.T. and Li, Q., 2011, “Adaptive disturbance tracking control for large horizontal 602 axis wind turbines with disturbance estimator in region ii operation," 49th AIAA Aerospace Sciences 603 Meeting including the New Horizons Forum and Aerospace Exposition, Orlando, FL, January 4-7. 
604 [26] Magar, K.T., Balas, M.J., and Frost, S.A., 2016, "Direct adaptive torque control for maximizing the 605 power captured by wind turbine in partial loading condition,” Wind Energy, V19 (5), pp. 911-922.

606 [27] Xia, Z., and Tang, J., 2013, "Characterization of dynamic response of structures with uncertainty by 607 using Gaussian processes,” Journal of Vibration and Acoustics, V135 (5), pp. 051006.

608 [28] Moriarty, P.J., and Hansen, A.C., 2005, AeroDyn Theory Manual, Technical Report No. NREL/TP609 500-36881, National Renewable Energy Laboratory, Golden, CO.

610 [29] Jonkman, J.M., and Buhl Jr., M.L., 2005, FAST User's Guide, Technical Report No. NREL/EL-500611 38230, National Renewable Energy Laboratory, Golden, CO.

612 [30] Hansen, M.H., Hansen, A.D., Larsen, T.J., Øye, S., Sørensen, P., and Fuglsang, P., 2005, Control 613 Design for a Pitch-Regulated, Variable Speed Wind Turbine, Technical Report Ris $\emptyset-R-1500(E N)$, Ris $\emptyset$ 614 National Laboratory, Roskilde, Denmark.

615 [31] Johnson, C., 1976, "Theory of disturbance-accommodating controllers," Control and Dynamic 616 Systems, V12, pp. 387-489.

617 [32] Balas, M.J., Lee, Y.J. and Kendall, L., 1998, "Disturbance tracking control theory with application to 618 horizontal axis wind turbines," Proceedings of 1998 ASME Wind Energy Symposium, Reno, NV, 619 January 12-15, pp. 95-99.

620 [33] Wen, J.T.Y., and Balas, M.J., 1989, "Robust adaptive control in Hilbert space," Journal of 621 Mathematical Analysis and Applications, V143 (1), pp. 1-26.

622 [34] Lee, Y., and Balas, M.J., 1995, “Adaptive control of persistent disturbance based on direct model 623 reference adaptive control," 36th Structures, Structural Dynamics and Materials Conference, New Orleans, 624 LA, April 10-13, pp. 3466-3473.

625 [35] Jonkman, J.M., 2009, TurbSim User's Guide: Version 1.50, Technical Report No. NREL/TP-500626 46198, National Renewable Energy Laboratory, Golden, CO.

627 [36] Hayman, G.J. and Buhl Jr, M., 2012, Mlife Users Guide for Version 1.00, Technical Report, 628 National Renewable Energy Laboratory, Golden, CO.

629 [37] Hayman, G., 2912, MLife Theory Manual Version 1.00, Technical Report, National Renewable 630 Energy Laboratory, Golden, CO.

631 [38] Kwakernaak, H., and Sivan, R., Linear Optimal Control Systems, Wiley-interscience, New York, NY, 6321972.

633

\section{Appendix}

$635 \quad \mathbf{K}$ refers to the nominal stiffness matrix in the reduced-order model without uncertainty. $\tilde{\mathbf{K}}$ refers to 636 the stiffness matrix under uncertainty. In this research we let the mean stiffness change be -0.05 and the 637 variance be $10^{-5}$. K and an example of $\tilde{\mathbf{K}}$ are shown below for comparison, i.e., 
638

$\mathbf{K}=\left[\begin{array}{ccccc}-334.77 & -343.22 & 932.55 & 932.81 & 932.73 \\ -334.77 & 8.68 \times 10^{8} & 932.55 & 932.81 & 932.77 \\ 27.06 & 27.12 & 1.93 \times 10^{4} & 0.01 & 0.0363 \\ 26.89 & 26.75 & 0.0511 & 1.93 \times 10^{4} & 0.02 \\ 27.22 & 27.03 & 0.0202 & 0.05 & 1.93 \times 10^{4}\end{array}\right]$

639 and

640

$\tilde{\mathbf{K}}=\left[\begin{array}{ccccc}-302.87 & 17.72 & 1.20 \times 10^{3} & 1.20 \times 10^{3} & 1.20 \times 10^{3} \\ -302.87 & 8.68 \times 10^{8} & 1.20 \times 10^{3} & 1.20 \times 10^{3} & 1.20 \times 10^{3} \\ 28.20 & 28.48 & 1.85 \times 10^{4} & 2.40 \times 10^{-3} & 0.05 \\ 28.40 & 28.69 & 0.0267 & 1.85 \times 10^{4} & 1.8 \times 10^{-3} \\ 28.50 & 28.66 & 0.0202 & 0.03 & 1.85 \times 10^{4}\end{array}\right]$

641 